\title{
Spatio-temporal distribution of nitrogen in the undulating littoral zone of Lake Taihu, China
}

\author{
Hongjun Wang · Jinwei Lu • Weidong Wang • \\ Peisheng Huang $\cdot$ Chengqing Yin
}

(C) Springer Science+Business Media B.V. 2007

\begin{abstract}
Spatio-temporal distribution of nitrogen was examined along the gradient from open water to lakeshore in Lake Taihu, China. Two types of undulating littoral zones were selected: natural reed belt and bare lakeshore. The reed belt affected nitrogen transformation and was sink for internal-lake nitrogen, whereas the bare lakeshore showed little effect. During the growing season, $\mathrm{NO}_{3}^{-}-\mathrm{N}$ concentration increased by up to 3-5 times from open water to reed belt, while $\mathrm{NH}_{4}^{+}-\mathrm{N}$ concentration decreased. It suggested that nitrification was the main nitrogen process in reed belt. Total dissolved nitrogen (TDN) showed little spatial variation, indicating that most of nitrogen released from sediment did not move into open water again. Significant temporal
\end{abstract}

Guest editors: B. Qin, Z. Liu \& K. Havens

Eutrophication of shallow lakes with special reference to Lake Taihu, China

H. Wang · J. Lu · W. Wang · C. Yin ( $ه)$

SKLEAC, Research Center for Eco-Environmental

Sciences, CAS, Beijing 100085, P.R. China

e-mail: cqyin@263.net

H. Wang · J. Lu

Graduate University of the Chinese Academy of

Sciences, Beijing 100039, P.R. China

P. Huang

Institute of Hydrobiology, Ji'nan University,

Guangzhou 510632, P.R. China variation of dissolved nitrogen occurred and was similar in both the littoral zone and the open water. Maximum TDN and $\mathrm{NH}_{4}^{+}-\mathrm{N}$ concentrations occurred in January, and $\mathrm{NO}_{3}^{-}-\mathrm{N}$ in March. Minimum $\mathrm{NH}_{4}^{+}-\mathrm{N}$ and $\mathrm{NO}_{3}^{-}-\mathrm{N}$ concentrations occurred in July and August, respectively. An increasing total soil nitrogen was found in the surface sediments from reed belt to open water. This further suggested that the reed-covered littoral zone had strong nitrogen transformation potential.

Keywords Nitrogen - Distribution - Spatial · Temporal $\cdot$ Littoral zone

\section{Introduction}

Riparian zone, the transitional boundary between terrestrial and aquatic ecosystems, influences water movement and waterborne contaminants (Fennessy \& Cronk, 1997) and is the principal route for transport of allochthonous matter from terrestrial to aquatic systems (Naiman et al., 1989). Many studies have shown that riparian buffer strips with small dimensions but playing a disproportionately large role, can attenuate terrestrial non-point source pollutants, including sediment, phosphorus and nitrogen (Cooper et al., 1987; Yin \& Lan, 1995; Bratli et al., 1999). Recent industrial growth and intensive 
agriculture have resulted in many riparian zones being disturbed or destroyed (Mitsch, 1995). If $70-95 \%$ of natural riparian systems are disturbed or destroyed, the landscape would lose much of its water purification and protection capacity (Fennessy \& Cronk, 1997). In China, many lakes, such as Lake Taihu (Hu et al., 1998) and Lake Chaohu (Xu et al., 2003), have deteriorated with nutrient loading sufficiently high to maintain a eutrophic state, even after external nutrient source reduction (Xu et al., 2003). Removing internal nutrients from aquatic systems may help control eutrophication. Dredging sediment from lakes is a direct, physical method ( $\mathrm{Xu}$ et al., 2003), but it is expensive and difficult to apply to the whole lake. Instead, it is urgent to find alternative biological techniques based on natural processes.

Lake Taihu is an important drinking water source and supports local agriculture, tourism and fisheries. Since the 1980s, rapid industrial development, heavy application of chemical fertilizers and intensive use of water resources have resulted in nutrient-rich water discharge into the lake, causing hyper-eutrophication. According to the Chinese environmental quality standards for surface water (GB 3838-2002), Lake Taihu water quality has deteriorated from grade I-II to grade IV-V, affecting life and economic development. Thus, studies on improving water quality, via nonpoint and point pollutant attenuation schemes, have been carried out in Lake Taihu (Dou et al., 1995; Pu \& Hu, 1996). While internal pollution and sediment/water interactions are stronger in shallow versus deep lakes (Threlkeld, 1994), internal loading may result from accumulation of pore water nutrients and subsequent release across the sediment-water interface in shallow lakes (Kleebery \& Kozerski, 1997). Internal nutrient loading from sediments may have an equal or greater contribution than external loading from the watershed (Detenbeck et al., 1993). Reducing internal nutrient loading is difficult, especially with respect to nitrogen, which is comparatively active.

Riparian zones can decrease the energy of flowing water, often resulting in increased sedimentation (Naiman et al., 1989). Finer suspended or resuspended sediment with abundant labile nutrient and absorbed pollutants (Naiman \& Décamps, 1997) carried by flowing water enrich riparian sediments proportionally (Johnston et al., 1984). Whether riparian zones will be a sink or source to open water is not clear. A review of nutrient budgets for lacustrine wetlands revealed that the lakeshore could be a net sink for nitrogen and phosphorus either seasonally or annually (Van der Valk et al., 1978). Prentki et al. (1978) suggested that wetland plants and macrophytes act as nutrient pumps from the sediment, while Sager et al. (1985) implied that lakeshore marshes act as nutrient transformers rather than nutrient sinks. If plant-covered littoral zones can act as nutrient sinks, with nutrients mostly converted to inactive forms with low mobility and bioavailability or removed completely, then the riparian zones could mitigate internal pollution. However, little information is available, since most researchers have focused on non-point source or external pollutant removal (Mitsch, 1995). To explore this problem, two types of littoral zones with different plant coverage and lacking terrestrial inputs were selected. In the first year, we mainly developed some fundamental work for our further long-term research in the two littoral zones, involving water, sediment, plant and phytoplankton, and focused on nitrogen in this paper.

Riparian zones are biogeochemical hot-spots for nitrogen (Cirmo \& McDonnell, 1997), where complicated nitrogen transformations take place. Nitrogen distribution is a function of physical, chemical and biological processes in the water column and sediments (Watts et al., 1998). Spatio-temporal distribution of nitrogen in mesocosmic environments may be representative of such processes. This paper presents results of a 13-month field study on spatio-temporal nitrogen distribution in the littoral zone of Meiliang Bay, Lake Taihu.

\section{Materials and methods}

Lake Taihu is a shallow, eutrophic lake in Jiangsu Province, East China. Monsoon climate dominates this region with annual mean air temperature of $14.9-16.2^{\circ} \mathrm{C}$ and a growing season lasting from April to November. Meiliang Bay, in the 
Fig. 1 Sampling station distribution in Sites A and $\mathrm{B}$

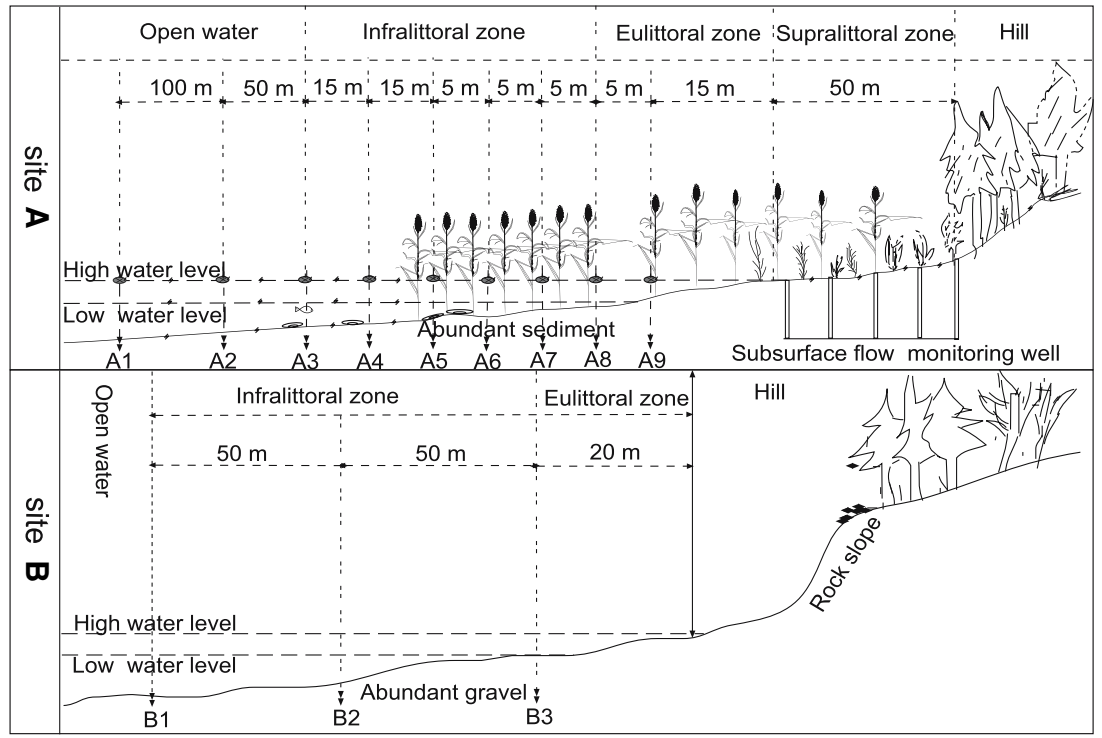

northern part of the lake, is hyper-eutrophic. Two types of littoral zones with differing plant coverage and one open water site (control) were chosen in Meiliang Bay (Fig. 1). Site A is a reed-covered littoral zone with an above-ground dry biomass density of $3-4 \mathrm{~kg} \mathrm{~m}^{-2}$, and Site B is a bare zone without plants. Site A is covered by a welldeveloped reed population with few other macrophytes. From open water, the first $25 \mathrm{~m}$ is inundated continuously, and the next $20 \mathrm{~m}$ is inundated intermittently. Toward land, the first $50 \mathrm{~m}$ are dominated by a reed (Phragmites australis) community and Gramineae, then a change from herbs to shrubs toward hills. All shrub stands are at least 30 years old, dominated by Myrica rubra, Symplocos setchensis, Loropetalum chinense and Eurya murica, and without visual evidence of recent natural or human disturbance, such as fire, wind-throw, logging or widespread insect infestation. In the lake-ward zone, there are sparse macrophytes with Myriophyllum verticillatum predominant in spring. The lake bottom is overlain by $30-40 \mathrm{~cm}$ soft sediment. Site B is a bare zone with little bottom sediment, and the interface between water and hills is cliff rock about $10 \mathrm{~m}$ wide. Shore vegetation resembles Site A with abundant shrubs. The open water site (C) is regarded as a control point. Initially, Site C was about $500 \mathrm{~m}$ from shore. After three preliminary surveys, due to little variation from 100 to
$500 \mathrm{~m}$, another station about $200 \mathrm{~m}$ from Site A was chosen as the control point.

To collect water and sediment and reduce sampling disturbance, a sampling bridge $(50 \mathrm{~cm}$ width, $60 \mathrm{~m}$ long) was built from dry shore to open water at Site A. To investigate subsurface water in the supralittoral zone, a soil auger $(\varnothing=11.5 \mathrm{~cm})$ was used to dig 5 vertical holes about $2 \mathrm{~m}$ deep as monitoring wells, and polypropylene pipes $(\varnothing=11 \mathrm{~cm})$ equipped with nylon netting $(<300 \mu \mathrm{m})$ at the bottom were inserted into the wells.

Nine sampling stations at Site $\mathrm{A}$ and three at Site B were established for monthly sampling along open water to lakeshore (Fig. 1), named A1-A9 and B1-B3, respectively. The interval distances of stations A1-A9 were 100, 50, 15, 15, $5,5,5$ and $5 \mathrm{~m}$, respectively, with A9 10-15 m from the lake edge at high water, A5 at the fringe of the reed belt, and A1-A4 in the water without macrophytes. On occasion, low water levels left A9 out of water. At Site B, the interval was $50 \mathrm{~m}$. Sampling stations were selected after an extensive survey of hydrochemistry reflecting the fringe effect of reed belt.

Monthly water sampling was carried out from Sep. 2003 to Sep. 2004. At each sampling, after 4-5 days of calm water, triplicate samples were taken using a 3-m long tube providing a vertical sample from the whole water column (Présing 
et al., 2001). Samples were placed in acid-washed polyethylene bottles and stored in a heat-preservation box on site. Dissolved oxygen (DO), $\mathrm{pH}$, and Eh were measured in situ using an oxygen meter (YSI Model 57) and a $\mathrm{pH} / \mathrm{Eh}$ meter (HI 8424 Microcomputer HANNA), respectively. In the laboratory, $250 \mathrm{ml}$ from each water sample was filtered within $24 \mathrm{~h}$ for analyses of nutrient and chlorophyll- $a$ concentrations. Ammonium nitrogen $\left(\mathrm{NH}_{4}^{+}-\mathrm{N}\right)$, nitrate nitrogen $\left(\mathrm{NO}_{3}^{-}-\mathrm{N}\right)$, nitrite nitrogen $\left(\mathrm{NO}_{2}^{-}-\mathrm{N}\right)$, and chlorophyll- $a$ (chla) were determined using APHA standard methods (APHA, 1998). Total nitrogen (TN), total phosphorus (TP), total dissolved nitrogen (TDN), and total dissolved phosphorus (TDP) were determined by peroxodisulfate oxidation (Ebina et al., 1983) in original water samples and filtrates, respectively. Total particulate nitrogen (TPN) and total particulate phosphorus (TPP) were calculated as the difference between $\mathrm{TN}$ and TDN, and TP and TDP, respectively.

About $300-400 \mathrm{~g}$ wet weight of mixed sediment $(0-10 \mathrm{~cm})$ and surface sediment $(0-1 \mathrm{~cm})$ was collected in duplicate using an Ekmanbottom sampler (Hydro-Bios, Kiel, Germany). At Site B, no sediment was present or collected. Sediment samples were stored in polyethylene bags and air-dried in the laboratory. Dried sediments were sieved $(\leq 150 \mu \mathrm{m})$ for analyses of soil organic matter (OM) and total soil nitrogen (TSN) contents. OM was obtained from the loss on ignition $\left(500^{\circ} \mathrm{C}, 2 \mathrm{~h}\right.$; Zhu \& Carreiro, 2004), and TSN was determined by the semi-microdistillation method using a $\mathrm{K}_{2} \mathrm{SO}_{4}-\mathrm{CuSO}_{4}-\mathrm{Se}$ catalyst (Lao, 1996).

From Apr. to Sep. 2004, particle sedimentation rates were measured with three sediment traps (Wahbah \& Zughul, 2001) placed in different locations in the two littoral zones. Each trap consisted of a cylindrical plastic jar (19 cm height, $7 \mathrm{~cm}$ diameter) attached to a rope stretched by an anchor and subsurface buoy marked by a floating buoy. Traps were retrieved monthly, sampled and then redeployed. Material collected in the trap was oven-dried at about $60^{\circ} \mathrm{C}$ for measuring total weight, and TSN and OM contents were measured as described above.

For subsurface water, samples were collected twice in the growing (May and June 2004) and non-growing season (Jan. and Feb. 2004). Two days prior to sampling, stagnant water in each well was removed three times, allowing the water level to recover to its original level on the sampling day. Nutrient analyses were carried out as above.

Storm runoff may be an important nutrient source in littoral zone. During the study, storms with duration more than $1 \mathrm{~h}$ were few. Surface runoff samples in the littoral zone could not be collected during any of the storms, so overland runoff effects remain untested.

One-way ANOVA was used to test temporal and spatial differences by means of parameters. Unless otherwise noted, all significant differences were at a probability of 0.05 or less. All analyses were performed using SAS 8.01 software (SAS, Inc., Cary, NC, USA).

\section{Results}

Spatial distribution of inorganic and total nitrogen

At Site A, water column $\mathrm{NH}_{4}^{+}-\mathrm{N}$ and $\mathrm{NO}_{3}^{-}-\mathrm{N}$ concentrations exhibited opposite trends from open water to reed belt in the growing season (Fig. 2). $\mathrm{NH}_{4}^{+}-\mathrm{N}$ concentrations decreased from 3.3 to $1.5 \mathrm{mg} \mathrm{l}^{-1}$ in April and 1.5 to $0.7 \mathrm{mg} \mathrm{l}^{-1}$ in August, while $\mathrm{NO}_{3}^{-}-\mathrm{N}$ increased from 2.4 to $4.4 \mathrm{mg} \mathrm{l}^{-1}$ in April and 0.4 to $2.3 \mathrm{mg} \mathrm{l}^{-1}$ in August. Moreover, spatial variation was highly significant $(P<0.01)$ between the sampling points in reed belt. Figure 2 shows that reed belt fringe effects on open water extend to $20 \mathrm{~m}$, while between 50 and $100 \mathrm{~m}$ offshore, inorganic nitrogen concentrations change little. In the non-growing season, the spatial variation trend was similar to that in the growing season, but with a gentler gradient. From surface water in reed belt to subsurface water in supralittoral zone, each nitrogen form decreases in concentrations, except $\mathrm{NH}_{4}^{+}-\mathrm{N}$ in the growing season (Table 1). One-way ANOVA showed significant difference between reed belt and open water in the growing season $(P<0.01)$ but not in the non-growing season. At Site B, inorganic nitrogen concentrations in the shore were similar to those in open water and no significant variation was detected. 

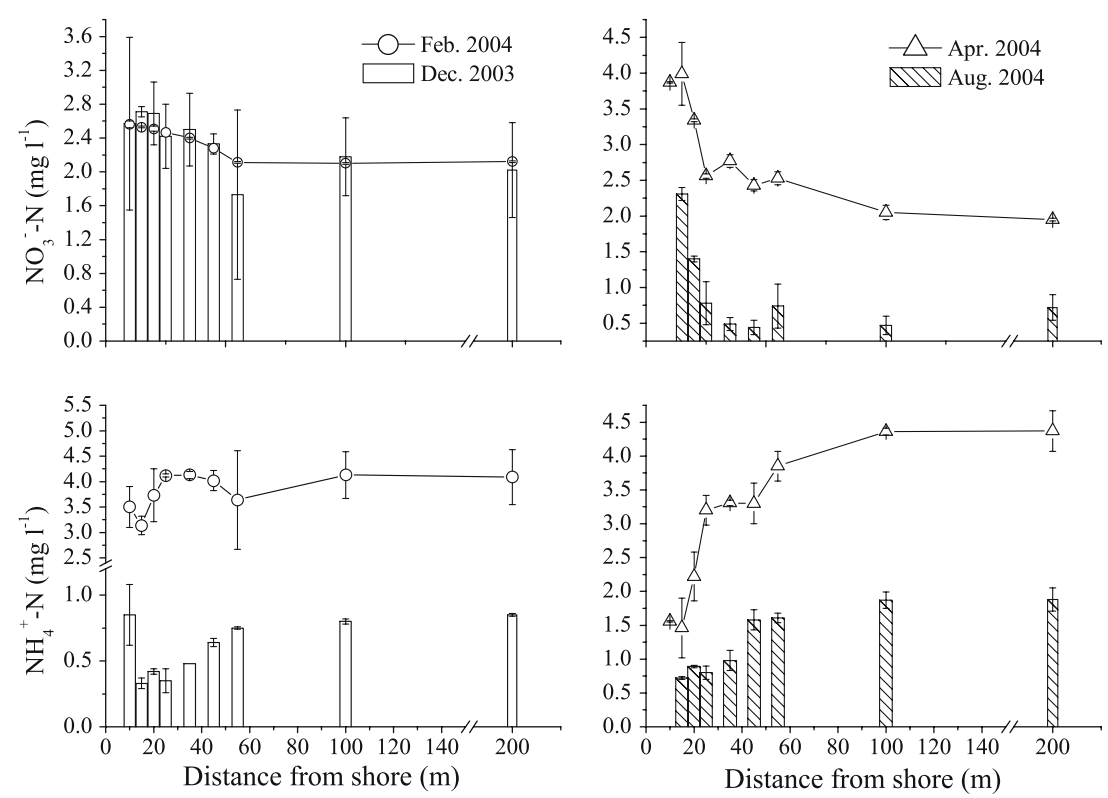

Fig. 2 Spatial variation of nitrate $\left(\mathrm{NO}_{3}^{-}-\mathrm{N}\right.$, top) and ammonium nitrogen $\left(\mathrm{NH}_{4}^{+}-\mathrm{N}\right.$, bottom) concentrations $(\mathrm{mean} \pm \mathrm{SD})$ in the reed-covered littoral zone (A) on two occasions

Table 1 The nitrogen forms in surface water of reed belt and subsurface water of supralittoral zone, $n=36$

\begin{tabular}{|c|c|c|c|c|}
\hline \multirow[t]{2}{*}{$\overline{\text { Parameters }\left(\mathrm{mg} \mathrm{l}^{-1}\right)}$} & \multicolumn{2}{|c|}{ Growing season $($ mean $\pm \mathrm{SD})$} & \multicolumn{2}{|c|}{ Non-growing season $($ mean $\pm \mathrm{SD})$} \\
\hline & Surface water & Subsurface water & Surface water & Subsurface water \\
\hline $\mathrm{NH}_{4}^{+}-\mathrm{N}$ & $0.37 \pm 0.26$ & $0.40 \pm 0.24$ & $3.37 \pm 0.37$ & $1.23 \pm 0.81$ \\
\hline $\mathrm{NO}_{3}^{-}-\mathrm{N}$ & $2.32 \pm 0.24$ & $0.52 \pm 0.59$ & $2.83 \pm 0.21$ & $1.28 \pm 0.59$ \\
\hline $\mathrm{NO}_{2}^{-}-\mathrm{N}$ & $0.12 \pm 0.14$ & $0.04 \pm 0.03$ & $0.22 \pm 0.13$ & $0.11 \pm 0.15$ \\
\hline $\mathrm{TN}$ & $4.17 \pm 1.15$ & $2.62 \pm 1.97$ & $17.72 \pm 7.82$ & $5.81 \pm 2.24$ \\
\hline
\end{tabular}

Spatial distribution of TN and TDN at Site A is shown in Fig. 3. TDN in reed belt varied little, and concentrations were similar to those in open water. Only at Station A9 at $10 \mathrm{~cm}$ water depth, TN concentrations increased from 12 to $28 \mathrm{mg} \mathrm{l}^{-1}$ and 4 to $54 \mathrm{mg} \mathrm{l}^{-1}$ in February and August, respectively. TN and TDN in the shore and open water was homogeneous at Site B.

Temporal variation of inorganic and total nitrogen

Temporal variations of $\mathrm{NH}_{4}^{+}-\mathrm{N}, \mathrm{NO}_{3}^{-}-\mathrm{N}$ and $\mathrm{NO}_{2}^{-}$ $\mathrm{N}$ in various zones are given in Fig. 4. Every form of nitrogen showed noticeable variation trend. $\mathrm{NH}_{4}^{+}-\mathrm{N}$ concentration maxima (3.2-5.2 $\mathrm{mg} \mathrm{l}^{-1}$ ) occurred in January, with temperature rise and increasing biological activities and $\mathrm{NH}_{4}^{+}-\mathrm{N}$ concentrations decreased to $0.3-0.9 \mathrm{mg} \mathrm{l}^{-1}$ in September. $\mathrm{NO}_{3}^{-} \mathrm{N}$ concentrations reached highest values (2.9-4.8 $\mathrm{mg} \mathrm{l}^{-1}$ ) in March, with a "lag" of about 2 months, and the minimum value occurred in August. Temporal variation of $\mathrm{NO}_{2}^{-}-\mathrm{N}$ concentrations showed peak values $\left(1.4\right.$ and $\left.0.7 \mathrm{mg} \mathrm{l}^{-1}\right)$ in May and September, respectively.

TN can be categorized as two components, TDN and TPN. There was a similar temporal trend between open water and bare littoral zones (Fig. 5). Maxima for TN (14.9-18.8 $\mathrm{mg} \mathrm{l}^{-1}$ ) and TDN (9.8-11.6 $\mathrm{mg} \mathrm{l}^{-1}$ ) occurred in January while minima in summer. TPN was highest (4.4$\left.11.1 \mathrm{mg} \mathrm{l}^{-1}\right)$ in winter and lowest $\left(0.5-1.6 \mathrm{mg} \mathrm{l}^{-1}\right)$ in spring. However, irregular TN and TPN patterns were observed in the reed-covered littoral 

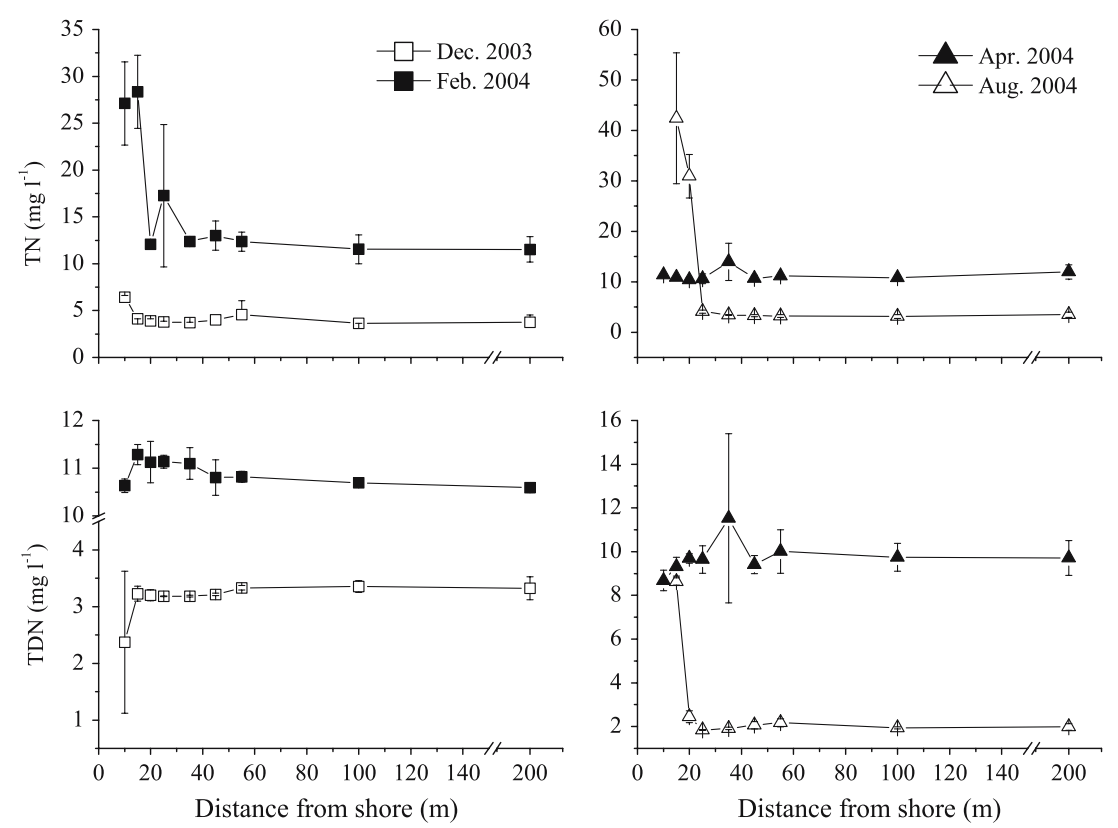

Fig. 3 Spatial distribution of total nitrogen (TN, top) and total dissolved nitrogen (TDN, bottom) concentrations (mean $\pm \mathrm{SD}$ ) in the reed-covered littoral zone $(\mathrm{A})$

zone, with peaks in summer and winter, respectively. From July to August, an algal bloom developed, and algae accumulated in reed belt $\left(100,000-300,000 \mu \mathrm{g} \mathrm{l^{-1 }}\right.$ chl- $\left.a\right)$, so there was an extraordinary peak value (about $30 \mathrm{mg} \mathrm{l}^{-1}$ ) of TPN with a positive correlation between TN and chl- $a$ in summer $\left(r^{2}=0.925, P<0.0001\right)$.

\section{Spatial variation of TSN and OM in sediment}

In the reed-covered littoral zone, there were plentiful soft sediments about $30-40 \mathrm{~cm}$ in thickness. Most were freshly settled from suspension in open water where mechanical energy is dampened by littoral reed stands. These sediments were dominated by decayed algae rich in nutrients, and TSN and OM contents in vertical mixed sediment $(0-10 \mathrm{~cm})$ were up to $0.5-0.6 \%$ and $7-8 \%$, respectively. TSN and OM contents in vertical mixed sediment had little spatial variation, however, they decreased from $0.5-0.6 \%$ to $0.1-0.2 \%$ and $7-8 \%$ to $2-3 \%$ in surface sediment $(0-1 \mathrm{~cm})$, respectively from open water to reed belt (Fig. 6).

\section{Discussion}

External sources of nitrogen in the littoral zone

Littoral zone is the interface between terrestrial and aquatic systems, and its dynamics are influenced by both. External nitrogen sources mainly come from land and open water, and the contribution from wet precipitation is negligible $\left(0.18 \mathrm{~g} \mathrm{~m}^{-2} \mathrm{a}^{-1}\right.$ in the case of Lake Taihu: Qin et al., 2004). Nitrogen enters littoral zone via surface runoff and subsurface flow from land. There were no conspicuous point sources, such as a factory or village, or non-point pollution sources in this study. Vegetation covered the littoral zone, and the rainy season coincided with vegetation density, where plants dampened the energy of flowing water and retained most waterborne materials with little subsequent erosion. However, there were few long duration rainstorms. Five surface runoff events were observed, but overland transport to littoral zone was not detected. Although some heavy rainstorms may 

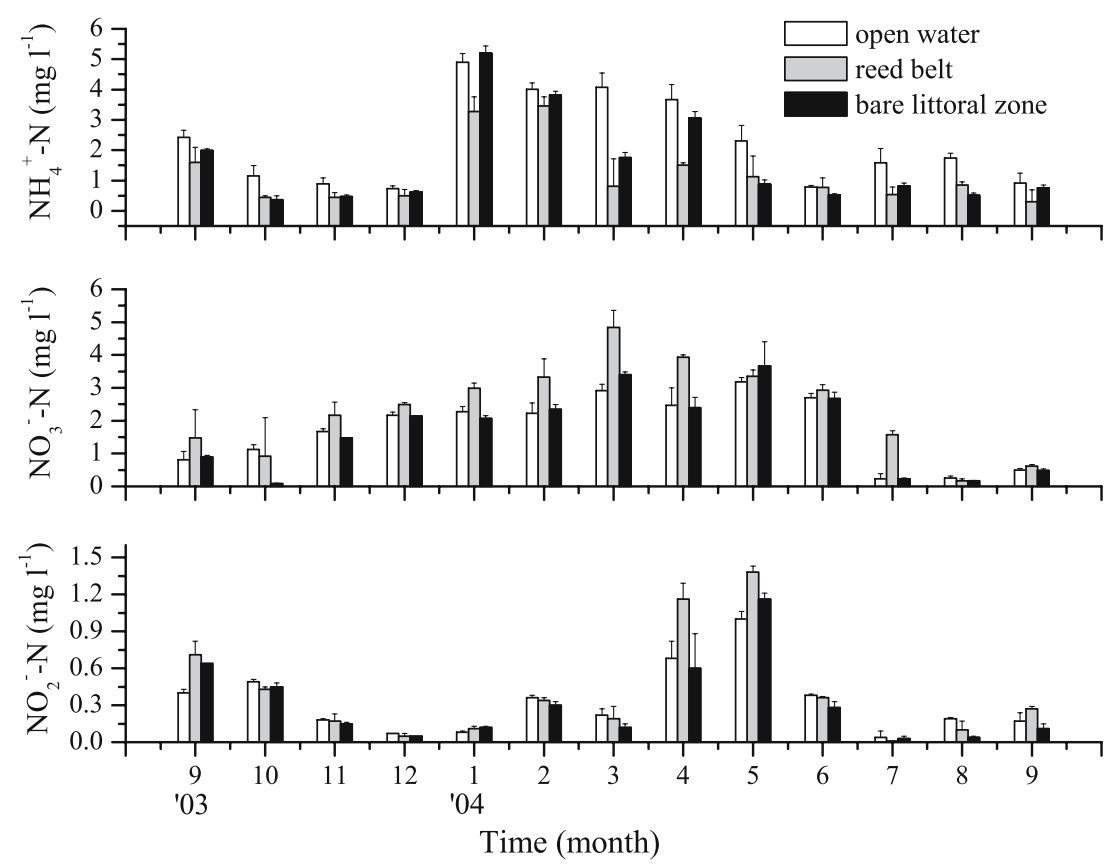

Fig. 4 Temporal variation of ammonium nitrogen $\left(\mathrm{NH}_{4}^{+}-\mathrm{N}\right)$, nitrate nitrogen $\left(\mathrm{NO}_{3}^{-}-\mathrm{N}\right)$, and nitrite nitrogen $\left(\mathrm{NO}_{2}^{-}-\mathrm{N}\right)$ concentrations (mean $\pm \mathrm{SD})$ in open water, reed belt and bare littoral zone

have been missed, we believe they were few. In this study, overland runoff effects have been disregarded. Subsurface flow is mostly unidirectional toward aquatic systems across the terrestrial boundary (Naiman \& Décamps, 1997), and our investigation suggested that few nutrients came from subsurface flow. $\mathrm{TN}$ and $\mathrm{NO}_{3}^{-}-\mathrm{N}$ concentrations in subsurface water were less than those in the reed belt water column in the growing and non-growing seasons. Moreover, $\mathrm{NO}_{3}^{-}-\mathrm{N}$ concentrations decreased from the lakeside to the hill and was lowest in the saturated area, which indicates (1) subsurface flow can carry little $\mathrm{NO}_{3}^{-}-\mathrm{N}$ to the inundated littoral zone; and (2) water column $\mathrm{NO}_{3}^{-}-\mathrm{N}$ may infiltrate into the supralittoral zone; and (3) the littoral reed belt may remove $\mathrm{NO}_{3}^{-}-\mathrm{N}$ efficiently from infiltrated lake water, as found in Lake Baiyangdian (Wang et al., 2002).

Material retention was high in ecotones or riparian zones with a sharp decrease in the kinetic energy of wind or water (Naiman et al., 1989). In a eutrophic lake, the retentate contained abundant nutrients, which would enrich the riparian zone (Johnston et al., 1984). In the littoral, especially where there is a macrophyte cover, sediments carried by lake currents also may settle. In our study, there was a distinct difference between average sedimentation rates at Sites A and $B$ (250 and $75 \mathrm{~g} \mathrm{~m}^{-2} \mathrm{~d}^{-1}$, respectively). At Site A, 30-40 cm thick soft sediments contained $0.5-0.6 \%$ TSN and 7-8\% OM, while at Site B, there was almost no sediment and bottom gravels were exposed.

These preliminary investigations indicate that particulates from open water were the main nitrogen source to the reed-covered littoral zone, perhaps over $90 \%$ on a rough estimate. Reed-covered littoral zones may be a sink for internal TPN sources in the lake if these enriched areas do not release nitrogen back into open water. 


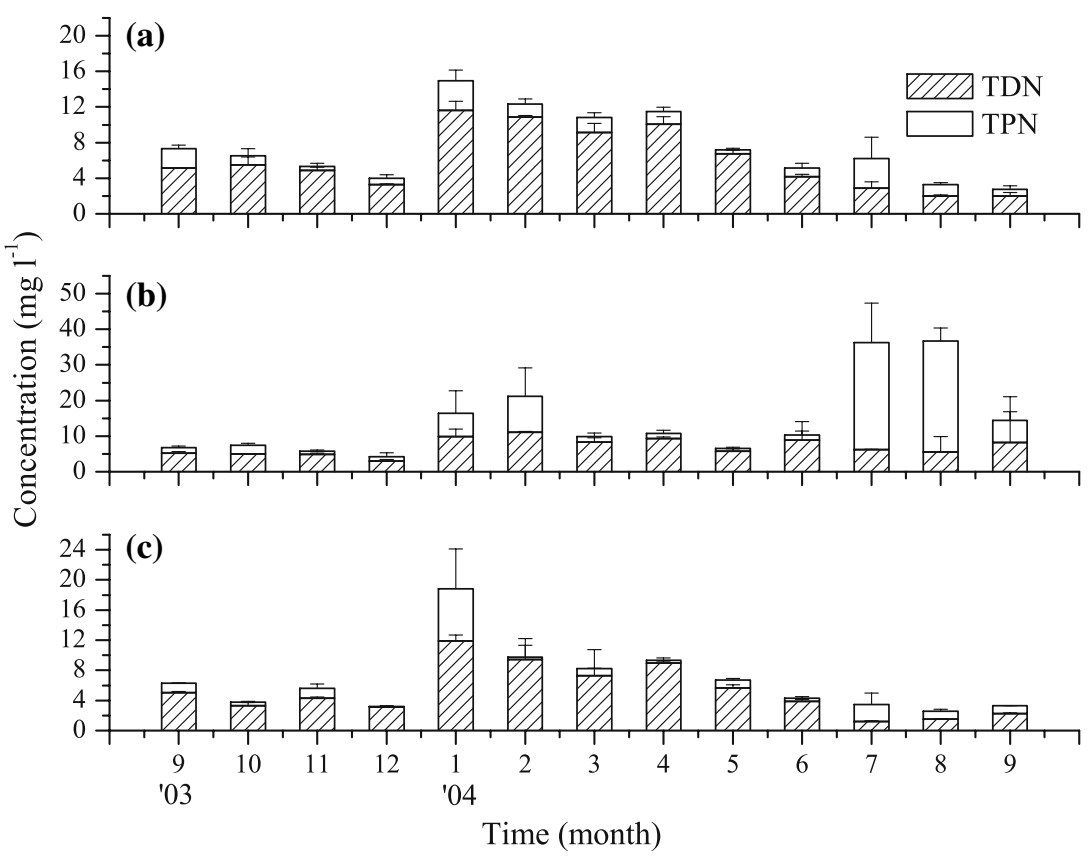

Fig. 5 Temporal variation of total dissolved nitrogen (TDN) and total particle nitrogen (TPN) in open water (a), reed belt (b), and bare littoral zone (c)

Spatial distribution of several forms of nitrogen

In the aquatic nitrogen cycle, energy utilization is more efficient and turnover is more rapid than in terrestrial systems (Heathwaite, 1993). Riparian zones may provide ideal conditions for nitrogen transformations, including ammonification, nitrification and denitrification (Fennessy \& Cronk, 1997). Continuous deposition of plant and algae detritus provides rich carbon sources. Many studies have shown that ammonification in vegetated sediments is higher than in bare sediments (Herbert, 1999: 570, Table 5). Nitrification and denitrification in vegetated sediments also may be high (Christensen \& Sørensen, 1986; Ottosen et al., 1999; Saunders \& Kalff, 2001; Matheson et al., 2002). There is enough oxygen for nitrification in surface sediment of shallow vegetated zones, and denitrification may occur at greater depths. However, wetland vegetation transports atmospheric oxygen through the stem, to the root, and into adjacent soil, which may oxidize the reduced microzone around the root surface (Armstrong, 1964; Brix \& Schierup, 1990). Two distinct layers are formed around a root surface favoring nitrification-denitrification (Reddy \& Patrick, 1984). Trapped sediments provide ammonification sites; nitrification can utilize ammonification product in the aerobic water, surface sediments and root surface; and denitrification occurs in the underlying sediment, releasing dinitrogen or nitrous oxide. These processes occur simultaneously and are controlled, in part, by $\mathrm{NH}_{4}^{+}-\mathrm{N}$ and $\mathrm{NO}_{3}^{-}-\mathrm{N}$ in the reed-covered littoral zone.

In the present study, there were opposite trends in $\mathrm{NH}_{4}^{+}-\mathrm{N}$ and $\mathrm{NO}_{3}^{-}-\mathrm{N}$ dynamics in the reed covered littoral zone. $\mathrm{NH}_{4}^{+}-\mathrm{N}$ concentrations decreased and $\mathrm{NO}_{3}^{-}-\mathrm{N}$ increased. In addition, other biotic factors influenced inorganic nitrogen concentrations, such as algal uptake and zooplankton and zoobenthos excretion. Moreover, $\mathrm{NH}_{4}^{+}-\mathrm{N}$ is taken up by cyanobacteria more rapidly than $\mathrm{NO}_{3}^{-}-\mathrm{N}$ or $\mathrm{NO}_{2}^{-}-\mathrm{N}$. Algae biomass in reed belt was not always higher than in open water, while the $\mathrm{NH}_{4}^{+}-\mathrm{N}$ concentration gradient existed at all times, especially in the growing season. These results implied that nitrification was more intensive than ammonification, and nitrification 

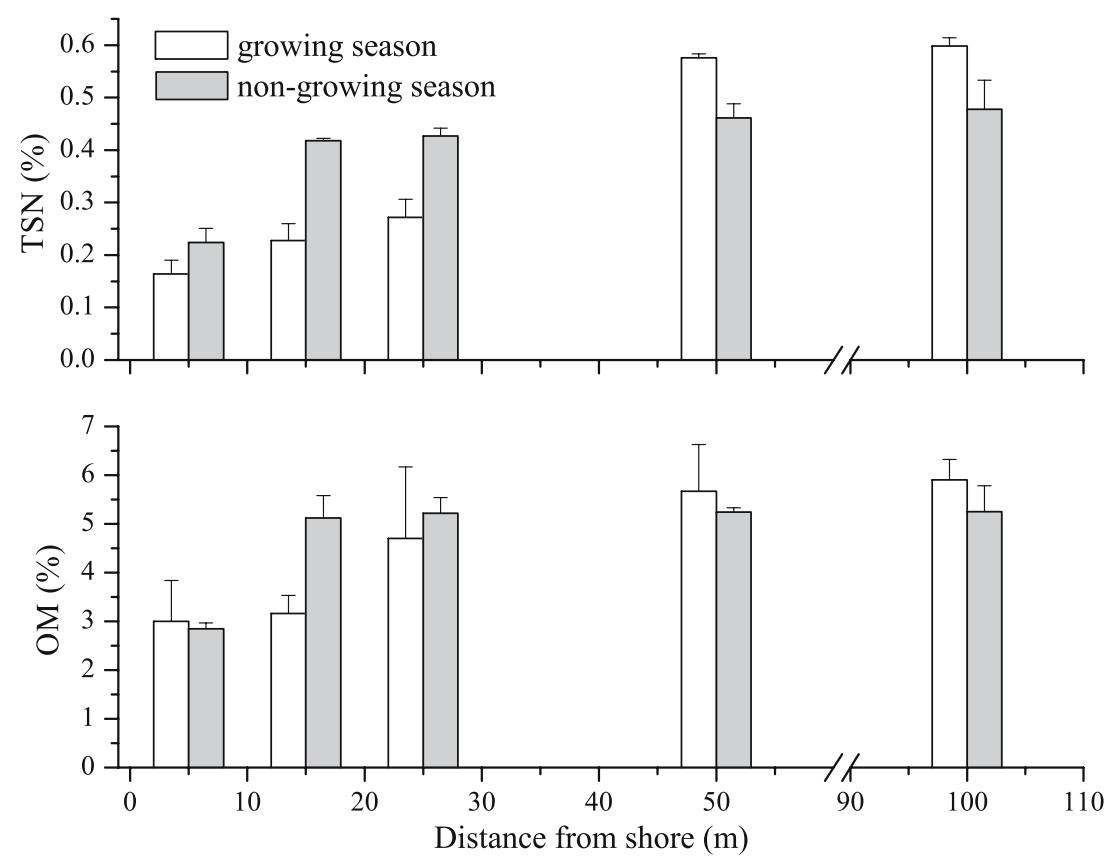

Fig. 6 Spatial variation of total soil nitrogen (TSN) and organic matter (OM) contents (mean \pm SD) in surface soft sediment in the reed-covered littoral zone (A)

exceeded denitrification. Our data are inadequate to explain the transformations, and further biotic research is needed.

Inorganic nitrogen forms variations showed that the plant-covered littoral zone is a strong transformer of nutrients. TN and TDN in water column, combined with TSN and OM in surface sediment, provide clues about their fates. Spatial variation of TN concentrations in reed belt varied but generally was higher than, and sometimes equal to, that in open water, while TDN concentrations showed little spatial variation. The difference between TN and TDN suggested that particulate nitrogen dominated the spatial variation of TN. In summer, chl- $a$ concentrations $\left(100,000-300,000 \mu \mathrm{g} \mathrm{l}^{-1}\right)$ in reed belt were 500 1,000 times higher than those in open water. Second, there was no or inconspicuous secondary nitrogen release into open water from the littoral zone. Furthermore, periodic high concentrations of particulate nitrogen indicate that these parti- cles mainly come from open water by intermittent wind forcing.

Denitrification is a key process of nitrogen removal from aquatic systems (Fennessy \& Cronk, 1997; Martina et al., 1999). Spatial variation of inorganic nitrogen suggested that it was not intensive in the present study. To verify this, we investigated surface sediment $(0-1 \mathrm{~cm})$ and found an interesting phenomenon. TSN and OM contents in surface sediment showed synchronous spatial variation with both decreasing from open water to reed belt. The decrease indicates that nitrogen in settling sediment is lost in reed belt via release or denitrification. Because the dissolved nitrogen bulk in littoral zone was similar to that in open water, we deduced that nitrogen decrease in surface sediment was removed by denitrification. The sediment results further demonstrated that the reed-covered littoral zone could act as nitrogen sink of the lake, which played a vital role in removing internal nutrients. 
Compared with the reed-covered littoral zone, spatial variation of nitrogen in bare zone was similar to that in open water. Lacking macrophytes, littoral zone erodes and particulates do not settle, so nutrients are not stored, and many biotic activities and biogeochemical cycles are limited. Altered physical conditions, when riparian zone is damaged, may result in loss of function (Fennessy \& Cronk, 1997).

Temporal variation of inorganic nitrogen and TN

Littoral zone is often a small part of the aquatic system, and temporal variation of dissolved nitrogen fractions are controlled by variations in open water. $\mathrm{TN}$ and $\mathrm{NH}_{4}^{+}-\mathrm{N}$ concentrations show winter maxima. These winter maxima possibly arise from (1) around lake, surface and subsurface catchment inputs are high in the non-growing season; (2) nutrients are concentrated in lower water levels; and (3) microbial activity is low due to low temperatures. $\mathrm{NO}_{3}^{-}-\mathrm{N}$ produced by nitrification, reaches peak value in spring often after a lag, since nitrification is sensitive to temperature. Below $15^{\circ} \mathrm{C}$, nitrification rates decrease (Focht \& Verstraete, 1977). In our study, TPN mainly came from suspended sediment and algae, and there were two maxima in reed belt (algae in summer, resuspended sediment in winter). While, in open water and bare zones, only one maxima in winter from suspended sediment was observed (Zhang et al., 2004).

\section{Conclusions}

Spatio-temporal distributions of different nitrogen forms were interpreted along gradients from open water to lakeshore in undulating littoral zones. In our two study zones, direct terrestrial nutrients accounted for little of the input, whereas more than $90 \%$ came from open water as resuspended sediments and algae. Between bare zone and reed-covered littoral zone, there were significant differences in hydrochemistry and physical conditions. The bare zone without soft sediment was almost homogeneous with open water, while the reed-covered littoral zone had abundant soft sediments and displayed spatial variations of inorganic nitrogen concentrations in water column. By comparison of spatial distribution of nitrogen in reed belt, the results showed that (1) nitrification was a key process controlling the nitrogen cycle in the reed-covered littoral zone, and most ammonification production was transformed in to nitrate; (2) little of the nitrogen enrichment to reed belt was released back into open water; (3) nitrification provided adequate nitrogen for denitrification; and (4) the reedcovered littoral zone was an important nitrogen sink. TSN and OM contents in surface sediments decreased from open water to reed belt. Denitrification appears to be significant in reed belt and most released nitrogen from sediments are removed, which further suggests that the reed covered littoral zone is a nitrogen sink and a selfbalancing system.

Acknowledgements This research was funded by Key Project of Knowledge Innovation Program of CAS (KZCX1-SW-12), National Hi-Tech Research Program (2002AA601011-05), and National Basic Research Program of China (2006CB403306).

\section{References}

APHA, 1998. Standard Methods for the Examination of Water and Wastewater, 20th ed. American Public Health Association, NW, Washington DC.

Armstrong, W., 1964. Oxygen diffusion from the roots of some British bog plants. Nature (London) 204: $801-802$.

Brix, H. \& H. H. Schierup, 1990. Soil oxygenation in constructed reed beds: the role of macrophyte and soil atmosphere interface oxygen transport. In Cooper, P. \& F. B. C. Findlater (eds), Constructed Wetlands in Water Pollution Control. Pergamon Press, London: 53-66.

Bratli , J. L., A. Skiple \& M. Mjelde, 1999. Restoration of Lake Borrevannet - self-purification of nutrients and suspended matter through natural reed belts. Water Science and Technology 40: 325-332.

Christensen, P. B. \& J. Sørensen, 1986. Temporal variation of denitrification activity in plant-covered littoral sediment from Lake Hampen, Denmark. Applied and Environmental Microbiology 51: 1174-1179.

Cirmo, C. P. \& J. J. McDonnell, 1997. Linking the hydrologic and biogeochemical controls of nitrogen transport in near-stream zones of temperate-forested catchments: a review. Journal of Hydrology 199: 88-120.

Cooper, J. R., J. W. Gilliam, R. B. Daniels \& W. P. Robarge, 1987. Riparian areas as filters for agricul- 
tural sediment. Soil Science Society of America Journal 51: 416-420.

Detenbeck, N. E., C. A. Johnston \& G. J. Niemi, 1993. Wetland effects on lake water quality in the Minneapolis/St. Paul metropolitan area. Landscape Ecology 8: 39-61.

Dou , H. S., P. M. Pu, S. Z. Zh, W. P. Hu \& Y. Pang, 1995. An experimental study on culture of Eichhornia crassipes (Mart.) Solms on open area of Taihu Lake. Journal of Plant Resources and Environment 4: 54-60 (in Chinese).

Ebina, J., T. Tsutsui \& T. Shirai, 1983. Simultaneous determination of total nitrogen and total phosphorus in water using peroxodisulfate oxidation. Water Research 17: 1721-1726.

Fennessy, M. S. \& J. K. Cronk, 1997. The effectiveness and restoration potential of riparian ecotones for the management of nonpoint source pollution, particularly nitrate. Critical Review in Environmental Science and Technology 27: 285-317.

Focht, D. D. \& W. Verstraete, 1977. Biochemical ecology of nitrification and denitrification. Advance in Microbial Ecology 1: 135-214.

Heathwaite, A. L., 1993. Nitrogen cycling in surface waters and lakes. In Burt, T. P., A. L. Heathwaite \& S. T. Trudgill (eds), Nitrate: Processes, Patterns and Management. John Wiley \& Sons Ltd., Chichester: 99-100.

Herbert, R. A., 1999. Nitrogen cycling in coastal marine ecosystems. FEMS Microbiology Reviews 23: 563-590.

Hu, W. P., J. Salomonsen, F. L. Xu \& P. M. Pu, 1998. A model for the effects of water hyacinths on water quality in an experiment of physico-biological engineering in Tai Lake, China. Ecological Modelling 107: 171-188.

Johnston, C. A., G. D. Bubenzer, G. B. Lee, F. W. Madison \& J. R. McHenry, 1984. Nutrient trapping by sediment deposition in a seasonally flooded lakeside wetland. Journal of Environmental Quality 13: 283-290.

Kleebery, A. \& H. P. Kozerski, 1997. Phosphorus release in Lake Grosser Muggelsee and its implications for lake restoration. Hydrobiologia 342: 9-26.

Lao, J. C., 1996. Soil agrochemical analysis methods [M], 2nd ed. Agricultural Press, Beijing.

Martina, T. L., N. K. Kaushik, J. T. Trevors \& H. R. Whiteley, 1999. Review: denitrification in temperate climate riparian zones. Water, Air, and Soil Pollution 111: 171-186.

Matheson, F. E., M. L. Nguyen, A. B. Cooper, T. P. Burt \& D. C. Bull, 2002. Fate of ${ }^{15} \mathrm{~N}$-nitrate in unplanted, planted and harvested riparian wetland soil microcosms. Ecological Engineering 19: 249-264.

Mitsch, W. J., 1995. Restoration of our lakes and rivers with wetlands - an important application of ecological engineering. Water Science and Technology 31: $167-177$.

Naiman, R. J. \& H. Décamps, 1997. The ecology of interface: Riparian zones. Annual Review of Ecology and Systematics 28: 621-658.
Naiman, R. J., H. Décamps \& F. Fournier (eds), 1989. The role of land/inland water ecotones in landscape management and restoration: a proposal for collaborative research. MAB Digest 4, UNESCO.

Ottosen, L. D. M., N. Risgaard-Petersen \& L. P. Neilsen, 1999. Direct and indirect measurements of nitrification and denitrification in the rhizosphere of aquatic macrophytes. Aquatic Microbiol Ecology 19: 81-91.

Prentki, R. T., T. D. Gustafson \& M. S. Adams, 1978. Nutrient movements in lakeshore marshes. In Good, R. E., D. F. Whigham \& R. L. Simpson (eds), Freshwater Wetlands: Ecological Processes and Management Potential. Academic Press, New York: 169-194.

Présing, M., S. Herodek, T. Preston \& L. Voros, 2001. Nitrogen uptake and the importance of internal nitrogen loading in Lake Balaton. Freshwater Biology 46: $125-139$.

Pu, P. M. \& W. P. Hu, 1996. Key strategies for controlling eutrophication of large shallow lakes in China. In 28th International Geographical Congress, Utrecht.

Qin, B. Q., W. P. Hu \& W. M. Chen, 2004. Process and mechanism of environmental changes of the Taihu Lake. Science Press, Beijing.

Reddy, K. R. \& W. H. Patrick, 1984. Nitrogen transformations and loss in flooded soils and sediments. CRC Critical Reviews in Environmental Control 13: 273-309.

Sager, P. E., S. Richman \& H. J. Harris, 1985. Preliminary observations on the flux of carbon, nitrogen, and phosphorus in a Great Lakes coastal marsh. In Prince, H. H. \& F. M. D'Itri (eds), Coastal Wetlands. Lewis Publishers, Inc., Chelsea, MI: 59-65.

Saunders, D. L. \& J. Kalff, 2001. Denitrification rates in the sediments of Lake Memphremagog, CanadaUSA. Water Research 35: 1897-1904.

Threlkeld, S. T., 1994. Benthic-pelagic interactions in shallow water columns: an experimentalist's perspective. Hydrobiologia 275/276: 293-300.

van der Valk, A. G., C. B. Davis, J. L. Baker \& C. E. Beer, 1978. Natural fresh water wetlands as nitrogen and phosphorus traps for land runoff. In Greeson, P. E., J. R. Clark \& J. E. Clark (eds), Wetland Functions and Values: The State of our Understanding. Proceeding of National Symposium on Wetlands, Lake Buena Vista, FL. American Water Resources Association, Minneapolis, MN: 457-467.

Wahbah, M. I. \& M. B. Zughul, 2001. Temporal distribution of chlorophyll $a$, suspended matter, and the vertical flux of particles in Aqaba (Jordan). Hydrobiologia 459: 147-156.

Wang, W. D., D. L. Wang \& C. Q. Yin, 2002. A field study on the hydrochemistry of land/inland water ecotones with reed domination. Acta Hydrochimica et Hydrobiologica 30: 117-127.

Watts, L. J., T. P. Rippeth \& A. Edwards, 1998. The roles of hydrographic and biogeochemical processes in the distribution of dissolved inorganic nutrients in a cottish Sea-loch: consequences for the spring phytoplankton bloom. Estuarine, Coastal and Shelf Science 46: 39-50. 
Xu, F. L., S. Tao, R. W. Dawson \& Z. R. Xu, 2003. The distributions and effects of nutrients in the sediments of a shallow eutrophic Chinese lake. Hydrobiologia 429: 85-93.

Yin, C. Q. \& Z. W. Lan, 1995. The nutrient retention by ecotone wetlands and their modification for Baiyangdian Lake restoration. Water Science and Technology 32: 159-167.
Zhang, Y. L., B. Q. Qin, W. M. Chen \& L. C. Luo, 2004. A study on total suspended matter in Tai Lake. Resources and Environment in the Yangtze Basin (in Chinese) 13: 266-271.

Zhu, W. X. \& M. M. Carreiro, 2004. Temporal and spatial variations in nitrogen transformations in deciduous forest ecosystems along an urban-rural gradient. Soil Biology \& Biochemistry 36: 267-278. 